\title{
Determining the mechanisms underlying augmented renal drug clearance in the critically ill: use of exogenous marker compounds
}

Andrew A Udy ${ }^{1,2^{*}}$, Paul Jarrett ${ }^{3}$, Janine Stuart ${ }^{3}$, Melissa Lassig-Smith ${ }^{3}$, Therese Starr ${ }^{3}$, Rachel Dunlop ${ }^{3}$, Steven C Wallis², Jason A Roberts ${ }^{2,3}$ and Jeffrey Lipman ${ }^{2,3}$

\begin{abstract}
Introduction: The aim of this study was to explore changes in glomerular filtration (GFR) and renal tubular function in critically ill patients at risk of augmented renal clearance (ARC), using exogenous marker compounds.

Methods: This prospective, observational pharmacokinetic (PK) study was performed in a university-affiliated, tertiary-level, adult intensive care unit (ICU). Patients aged less than or equal to 60 years, manifesting a systemic inflammatory response, with an expected ICU length of stay more than 24 hours, no evidence of acute renal impairment (plasma creatinine concentration $<120 \mu \mathrm{mol} / \mathrm{L}$ ) and no history of chronic kidney disease or renal replacement therapy were eligible for inclusion. The following study markers were administered concurrently: sinistrin 2,500 mg (Inutest; Laevosan, Linz, Austria), p-aminohippuric acid (PAH) 440 mg (4\% p-aminohippuric acid sodium salt; CFM Oskar Tropitzsch, Marktredwitz, Germany), rac-pindolol 5 or 15 mg (Barbloc; Alphapharm, Millers Point, NSW, Australia) and fluconazole 100 mg (Diflucan; Pfizer Australia Pty Ltd, West Ryde, NSW, Australia). Plasma concentrations were then measured at 5, 10, 15, 30, 60 and 120 minutes and 4, 6, 12 and 24 hours post-administration. Non-compartmental PK analysis was used to quantify GFR, tubular secretion and tubular reabsorption.

Results: Twenty patients were included in the study. Marker administration was well tolerated, with no adverse events reported. Sinistrin clearance as a marker of GFR was significantly elevated (mean, 180 (95\% confidence interval (Cl), 141 to 219) $\mathrm{ml} / \mathrm{min})$ and correlated well with creatinine clearance $(r=0.70, P<0.01)$. Net tubular secretion of PAH, a marker of tubular anion secretion, was also elevated (mean, $428(95 \% \mathrm{Cl}, 306$ to 550$) \mathrm{ml} / \mathrm{min})$, as was net tubular reabsorption of fluconazole (mean, 135 (95\% Cl, 100 to 169) $\mathrm{ml} / \mathrm{min}$ ). Net tubular secretion of (S)- and (R)-pinodolol, a marker of tubular cation secretion, was impaired.
\end{abstract}

Conclusions: In critically ill patients at risk of ARC, significant alterations in glomerular filtration, renal tubular secretion and tubular reabsorption are apparent. This has implications for accurate dosing of renally eliminated drugs.

\section{Introduction}

The kidneys have a crucial role in water and electrolyte homeostasis, acid-base balance, excretion of nitrogenous waste products and select endocrine functions. In terms of drug disposition, renal excretion of parent compounds or active metabolites represents a key route of drug elimination for many agents. This process involves

\footnotetext{
*Correspondence: a.udy@alfred.org.au

'Department of Intensive Care and Hyperbaric Medicine, The Alfred, 55

Commercial Road, Prahran, Melbourne, Victoria 3181, Australia

${ }^{2}$ Burns, Trauma, and Critical Care Research Centre, The University of

Queensland, Herston, Brisbane, Queensland 4029, Australia

Full list of author information is available at the end of the article
}

a combination of glomerular filtration, renal tubular secretion and renal tubular reabsorption. Net renal drug elimination represents the sum of these processes.

Recent research has highlighted that renal antibacterial drug elimination (particularly renally cleared $\beta$-lactams) can be significantly elevated in the critically ill [1], such that drug exposure is often suboptimal [1-3], and may lead to adverse clinical outcomes [4]. This phenomenon has been termed augmented renal clearance (ARC) [1], and is seen in association with an elevated urinary creatinine clearance $\left(\mathrm{CL}_{\mathrm{CR}}\right)$ [5]. Such measures have therefore been advocated as a useful tool to identify ARC in 
the critically ill $[6,7]$, the assumption being that elevated glomerular filtration is a key mechanism in this process.

However, measured $\mathrm{CL}_{\mathrm{CR}}$ suffers from the limitations inherent to using any endogenous filtration marker, such that variations in diet, muscle mass and physical activity may also influence plasma $\mathrm{CR}$ concentrations. In addition, $\mathrm{CL}_{\mathrm{CR}}$ provides limited mechanistic information on changes in renal tubular function. As such, renal drug handling in the critically ill requires additional research, ideally using exogenous indicators of renal function. One method involves the administration of multiple renal markers [8], such that the elimination of each can be used to quantify changes in glomerular filtration, and tubular drug handling, simultaneously. Using such a 'cocktail', Gross and colleagues applied this approach in 12 healthy male subjects [9], establishing useful baseline values for comparison.

The aims of this prospective observational study were therefore (1) to assess the feasibility and safety of administering multiple markers of renal function simultaneously in the intensive care unit (ICU), (2) to quantify glomerular filtration and renal tubular function in a cohort of critically ill patients at risk of ARC and (3) to compare these data with previously reported values in healthy volunteers.

\section{Material and methods \\ Setting}

This single-centre observational study was undertaken in a tertiary-level, university-affiliated ICU. Ethical approval was obtained from our institution's Human Research Ethics Committee (HREC/09/QRBW/15), with written informed consent obtained from either the patient or the nominated substitute decision-maker.

\section{Study population}

Study participants had to be aged $\leq 60$ years, have an expected ICU length of stay $>24$ hours, evidence of a systemic inflammatory response syndrome [10] in the 24 hours prior to marker administration, a plasma CR concentration $<120 \mu \mathrm{mol} / \mathrm{L}$ and no history of chronic kidney disease (CKD) or renal replacement therapy. Patients were excluded from receiving any study markers if (1) either invasive haemodynamic monitoring or an indwelling urinary catheter (IDC) was not employed as part of standard management; (2) they were $<18$ years of age; (3) they were pregnant; (4) rhabdomyolysis was clinically suspected or the plasma creatinine kinase level was $>5,000 \mathrm{IU} / \mathrm{L}$; (5) they were in the 'risk' category or greater for acute kidney injury, as defined by the risk, injury, failure, loss, and endstage (RIFLE) kidney disease criteria [11]; (6) there was a documented allergy and/or contraindication to one or more of the renal markers; (7) one or more markers were being employed clinically; or (8) the treating clinician considered the patient unsuitable for enrolment. Recruitment was carried out by convenience sampling.

\section{Data collection, dosing administration and sampling protocol}

Demographic data, including age, sex, height, weight, Acute Physiology and Chronic Health Evaluation (APACHE) II score and admission diagnosis were recorded prospectively. After confirming eligibility and obtaining consent, the following study markers were administered; sinistrin (Inutest; Laevosan, Linz, Austria) 2,500 mg in $10 \mathrm{ml}$ intravenously (IV) over 30 seconds, $4 \% \mathrm{p}$-aminohippuric acid sodium salt (PAH; CFM Oskar Tropitzsch, Marktredwitz, Germany) $440 \mathrm{mg}$ IV over 1 minute, rac-pindolol (Barbloc; Alphapharm, Millers Point, NSW, Australia) 5 or $15 \mathrm{mg}$ orally or via an enteral feeding tube and fluconazole (Diflucan; Pfizer Australia Pty Ltd, West Ryde, NSW, Australia) $100 \mathrm{mg}$ orally or via an enteral feeding tube.

Enteral markers were administered only if the patient was documented to be tolerant of enteral nutrition. rac-Pindolol was withheld if there was (1) a history of severe reactive airway disease (asthma and/or chronic obstructive airway disease) or symptomatic bradyarrhythmia or (2) moderate vasopressor support (>10 $\mu \mathrm{g} / \mathrm{min}$ infusion of noradrenaline or adrenaline) was being provided. Administration of all or a combination of markers was possible, depending on the patient profile.

Blood samples were then taken via the intra-arterial cannula at the following time points after marker administration: 5, 10, 15, 30, 60 and 120 minutes and 4, 6, 12 and 24 hours. Following collection, all blood samples were immediately placed on ice and centrifuged within 60 minutes at 3,000 rpm for 10 minutes. Plasma was then aliquoted off and stored for analysis at $-80^{\circ} \mathrm{C}$. All urine was collected via the IDC over the same 24-hour period, with a $10-\mathrm{ml}$ sample stored at $-80^{\circ} \mathrm{C}$ for later assays. The remaining urine was forwarded to the local hospital laboratory for biochemical analysis.

All marker administration was performed under medical supervision, with the patients receiving continuous cardiovascular and respiratory monitoring. All physiological parameters, fluid balance and any therapeutic interventions performed were recorded concurrently.

\section{Bioanalysis}

$(S)$-pindolol, $(R)$-pindolol, PAH and fluconazole in plasma and urine were measured by in-house liquid chromatography-tandem mass spectrometry methods validated in accordance with US Food and Drug Administration guidelines for bioanalysis. Separations were tailored for each analyte: a reverse-phase column was used for fluconazole; a hydrophilic interaction liquid chromatography column was used for PAH; and a chiral column was used for pindolol. Sinistrin was 
measured by using a commercially available enzymelinked immunosorbent assay kit (FIT-GFR; BioPAL, Worcester, MA, USA). CR was measured in plasma and urine by using an isotope dilution mass spectrometry traceable assay through the institutional pathology laboratory. For comparison, estimated GFR (eGFR) was calculated using the Chronic Kidney Disease Epidemiology Collaboration (CKD-EPI) formula [12].

\section{Data treatment and statistical analysis}

$\mathrm{CL}_{\mathrm{CR}}$ was determined from the urinary $\mathrm{CR}$ concentration, 24-hour urine volume and plasma CR concentrations obtained from routine clinical testing. If multiple plasma values were available over the 24-hour study period, the mean was used in subsequent analysis. Plasma concentrations of all renal markers were plotted on a concentration/ time graph, with the slope of the terminal portion calculated by linear regression. Suitability for use in further

Table 1 Demographic, illness severity and physiological data $^{a}$

\begin{tabular}{|c|c|}
\hline Variable & Data $(N=20)$ \\
\hline Age, yr, mean (95\% Cl) & $36.7(29.2$ to 44.1$)$ \\
\hline Males, $n$ (\%) & $12(60.0)$ \\
\hline Height, m, mean (95\% Cl) & 1.74 (1.68 to 1.79$)$ \\
\hline Weight, kg, mean (95\% Cl) & 80.2 (70.8 to 89.5$)$ \\
\hline Body surface area, $\mathrm{m}^{2}$, mean (95\% Cl) & 1.94 (1.81 to 2.07$)$ \\
\hline Days in ICU before sampling, mean ( $95 \% \mathrm{Cl})$ & 4.90 (3.74 to 6.06$)$ \\
\hline APACHE II score, mean (95\% CI) & $17.3(13.7$ to 20.8$)$ \\
\hline \multicolumn{2}{|l|}{ Diagnosis, $n(\%)$} \\
\hline Burns & $3(15.0)$ \\
\hline Trauma (including head injury) & $10(50.0)$ \\
\hline Neurological & $3(15.0)$ \\
\hline Sepsis & $3(15.0)$ \\
\hline Other & $1(5.0)$ \\
\hline Mechanically ventilated, $n$ (\%) & $19(95.0)$ \\
\hline Receiving vasopressor infusion, $n(\%)$ & $3(15.0)$ \\
\hline Pre-dose HR, beats/min, mean (95\% Cl) & $100(90.8$ to 110$)$ \\
\hline Pre-dose MAP, mmHg, mean (95\% Cl) & 89.4 (83.0 to 95.8$)$ \\
\hline Plasma CR, $\mu$ mol/L, mean (95\% Cl) & $64.5(53.2$ to 75.7$)$ \\
\hline Urinary CR, mmol/L, mean (95\% Cl) & $5.93(4.02$ to 7.85$)$ \\
\hline 24-hr urinary volume, L, mean (95\% Cl) & $3.10(2.35$ to 3.85$)$ \\
\hline Urinary $\mathrm{pH}$, mean $(95 \% \mathrm{Cl}), n=16$ & $6.16(5.75$ to 6.57$)$ \\
\hline 24-hr fluid balance, ml, mean (95\% Cl) & $700(-126$ to 1,527$)$ \\
\hline 24-hr CL $\mathrm{CR}_{\mathrm{R}}, \mathrm{ml} / \mathrm{min}$, mean $(95 \% \mathrm{Cl})$ & 168 (139 to 197$)$ \\
\hline CKD-EPI eGFR, ml/min, mean (95\% Cl) & 128 (113 to 144$)$ \\
\hline
\end{tabular}

${ }^{a} \mathrm{APACHE}$, Acute Physiology and Chronic Health Evaluation; $\mathrm{Cl}$, Confidence interval; $\mathrm{CL}_{\mathrm{CR}}$, Creatinine clearance; $\mathrm{CKD}$-EPI, Chronic Kidney Disease Epidemiology Collaboration; $C R$, Creatinine; eGFR, Estimated glomerular filtration rate; HR, Heart rate; ICU, Intensive care unit; MAP, Mean arterial pressure.
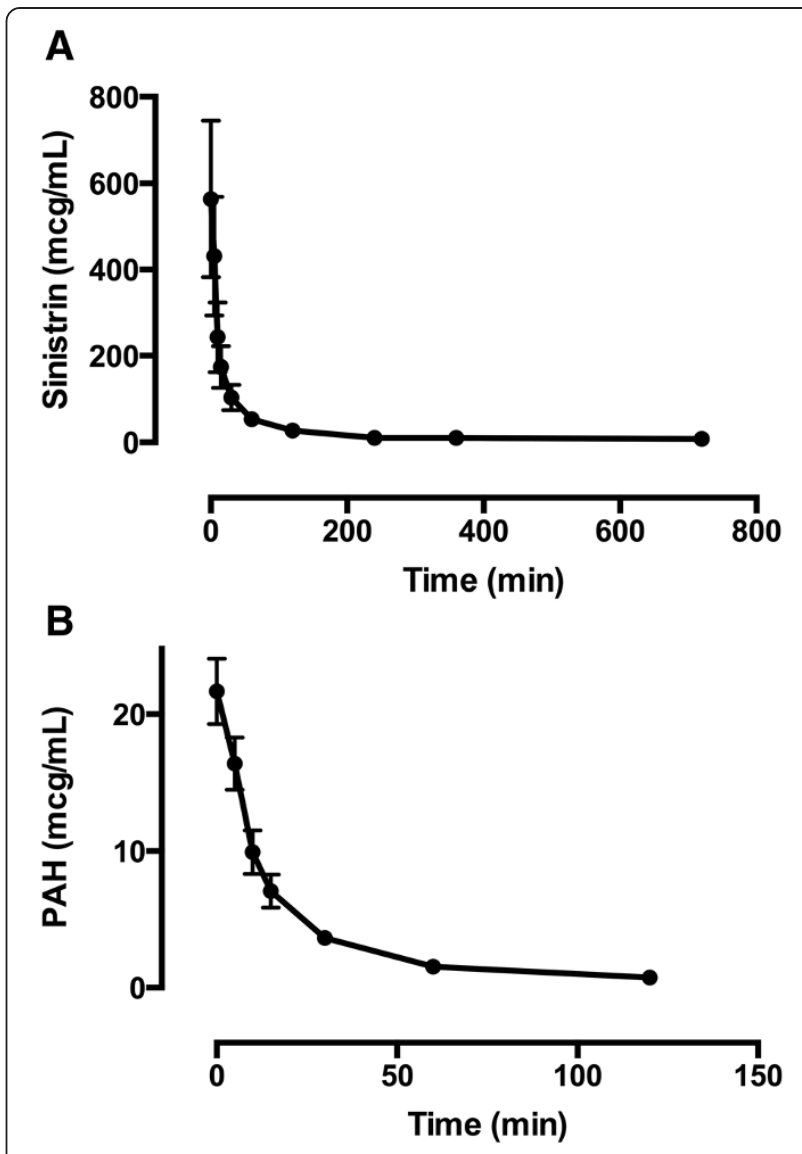

Figure 1 Plot of plasma concentration versus time for intravenous study markers. Mean (95\% confidence interval) plasma sinistrin (A) and p-aminohippuric acid (PAH) (B) concentrations ( $y$-axis) versus time ( $x$-axis) are shown.

analysis was assessed by visual inspection. Backward extrapolation to time zero was performed for those markers administered IV (sinistrin and PAH). The area under the plasma concentration/time curve $\left(\mathrm{AUC}_{0-\infty}\right)$ was determined using the linear trapezoidal rule and extrapolated to infinity by adding the product of the last measured plasma concentration multiplied by the terminal slope. As per previous recommendations, plasma concentrations to at least 120 minutes were required for accurate calculation of sinistrin $\mathrm{AUC}_{0-\infty}$ [13]. Plasma $\mathrm{CL}$ for each marker was then calculated as dose $/ \mathrm{AUC}_{0-\infty}$.

The total amount recovered in urine (Ae) of PAH, fluconazole and $(S)$ - and $(R)$-pindolol was calculated by multiplying the urinary concentration by the 24-hour urine volume. Renal clearance $\left(\mathrm{CL}_{\mathrm{R}}\right)$ was then calculated as $\mathrm{Ae} / \mathrm{AUC}_{0-\infty}$, and non-renal clearance $\left(\mathrm{CL}_{\mathrm{NR}}\right)$ as the difference of $C L-C L_{R}$. Sinistrin $C L$ was taken as representing the GFR, and PAH $C_{R}$ was taken as effective renal plasma flow (ERPF). The filtration fraction was calculated as GFR/ERPF. Glomerular filtration of the unbound marker was calculated as $f_{\mathrm{u}} \times \mathrm{GFR}$, where $f_{\mathrm{u}}$ is the 
Table 2 Pharmacokinetic analyses of individual markers ${ }^{\mathrm{a}}$

\begin{tabular}{|c|c|c|c|c|c|}
\hline & $\begin{array}{l}\text { Sinistrin } \\
(n=15)\end{array}$ & $\begin{array}{l}\text { PAH } \\
(n=19)\end{array}$ & $\begin{array}{l}\text { (S)-pindolol } \\
(n=14)\end{array}$ & $\begin{array}{l}\text { (R)-pindolol } \\
(n=14)\end{array}$ & $\begin{array}{l}\text { Fluconazole } \\
(n=18)\end{array}$ \\
\hline $\mathrm{AUC}_{0-\infty}, \mathrm{mcg} / \mathrm{ml} / \mathrm{min}$, mean $(95 \% \mathrm{Cl})$ & $16,513(12,247$ to 20,778$)$ & 426 (366 to 487) & 8.70 (3.07 to 14.3$)$ & $11.2(1.42$ to 21.0$)$ & $3,804(3,073$ to 4,535$)$ \\
\hline $\mathrm{CL}, \mathrm{ml} / \mathrm{min}$, mean $(95 \% \mathrm{Cl})$ & 180 (141 to 219$)$ & $1,139$ (943 to 1,335$)$ & 654 (465 to 842$)$ & 639 (393 to 884$)$ & 30.5 (24.4 to 36.6$)$ \\
\hline $\mathrm{Ae}, \mathrm{mg}$, mean $(95 \% \mathrm{Cl})$ & - & 230 (211 to 249$)$ & $0.80(0.36$ to 1.24$)$ & 0.77 (0.39 to 1.15$)$ & $35.9(27.4$ to 44.3$)$ \\
\hline $\mathrm{CL}_{\mathrm{R}}, \mathrm{ml} / \mathrm{min}$, mean $(95 \% \mathrm{Cl})$ & - & 594 (484 to 704) & 122 (77 to 167$)$ & 98 (68 to 129) & $12.3(7.61$ to 16.9$)$ \\
\hline $\mathrm{CL}_{\mathrm{NR}}, \mathrm{ml} / \mathrm{min}$, mean $(95 \% \mathrm{Cl})$ & - & 545 (439 to 652) & 532 (369 to 695) & 541 (310 to 772 ) & $18.2(15.5$ to 21.0$)$ \\
\hline $\mathrm{CL}_{\mathrm{NR}}$, mean $(95 \% \mathrm{Cl})$ & - & $47.8(43.5$ to 52.0$)$ & 80.9 (75.8 to 86.0) & 81.5 (76.3 to 86.8$)$ & 64.1 (55.7 to 72.6$)$ \\
\hline $\mathrm{CL}_{\mathrm{CR}}, \mathrm{ml} / \mathrm{min}$, mean $(95 \% \mathrm{Cl})$ & 156 (125 to 188$)$ & 164 (135 to 193$)$ & 166 (127 to 204) & 166 (127 to 204$)$ & 171 (140 to 203) \\
\hline
\end{tabular}

${ }^{\mathrm{a}} \mathrm{Ae}$, Amount recovered in urine; $\mathrm{AUC}_{0-\infty}$; Area under the concentration/time curve (extrapolated to infinity); $\mathrm{Cl}, \mathrm{Confidence} \mathrm{interval;} \mathrm{CL}, \mathrm{Clearance} ; \mathrm{CL}_{\mathrm{CR}}$, $\mathrm{Creatinine}$ clearance; $\mathrm{CL}_{\mathrm{NR}}$, Non-renal clearance; $\mathrm{CL}_{\mathrm{R}}$, Renal clearance; $\mathrm{PAH}, \mathrm{p}$-Aminohippuric acid.

unbound fraction in plasma. Tubular anion secretion was determined from the net tubular secretion of $\mathrm{PAH}$ as $\mathrm{CL}_{\mathrm{R}}-\left(f_{\mathrm{u}} \times \mathrm{GFR}\right)$. Tubular cation secretion was determined from the net tubular secretion of $(S)$ - and $(R)$ pindolol as $\mathrm{CL}_{\mathrm{R}}-\left(f_{\mathrm{u}} \times \mathrm{GFR}\right)$. Tubular reabsorption was estimated from the net reabsorption of fluconazole as $\left(f_{\mathrm{u}} \times\right.$ GFR) $-\mathrm{CL}_{\mathrm{R}}$ [8]. The $f_{\mathrm{u}}$ of PAH was taken as 0.83 [9]; for $(S)$ - and $(R)$-pindolol, it was 0.45 [14]; and for fluconazole, it was 0.83 [9].

Continuous data are presented as the mean (95\% confidence interval (CI)). Categorical data are presented as counts (\%). For bivariate correlation between continuous variables, we used a Pearson correlation coefficient $(r)$. A paired Student's $t$-test was used to compare intra-patient data. Bland-Altman analysis was employed to explore the agreement between sinistrin $C L, C_{C R}$ and CKD-EPI eGFR values. A double-sided $P$-value $<0.05$ was considered as statistically significant, and SPSS version 22 software (IBM, Armonk, NY, USA) was used for all analyses.

\section{Results}

Demographic, illness severity and physiological data Twenty adult patients were recruited into the study. Demographic, illness severity, therapeutic and physiological data are provided in Table 1. As presented, the subjects were mostly male, young and primarily admitted after trauma. As per the inclusion criteria, plasma CR concentrations were low; the mean was 64.5 (53.2 to 75.7) $\mu \mathrm{mol} / \mathrm{L}$. Twenty-fourhour $\mathrm{CL}_{\mathrm{CR}}$ measures were elevated (168 (139 to 197) ml/ min), whereas in comparison CKD-EPI eGFR estimates were significantly lower (128 (113 to 144$) \mathrm{ml} / \mathrm{min}, P<0.01$ ).

\section{Pharmacokinetic analyses of individual markers}

Sinistrin and PAH were administered IV to all 20 patients, with no adverse effects observed. Suitable sinistrin plasma concentration/time profiles could be plotted in 15 cases, which are presented in Figure 1. PAH concentrations were assessable in 19 cases, and these are also illustrated graphically in Figure 1 . Both sinistrin $\mathrm{CL}$ and $\mathrm{PAH} \mathrm{CL}_{\mathrm{R}}$ were elevated, although moderate inter-patient variation in these

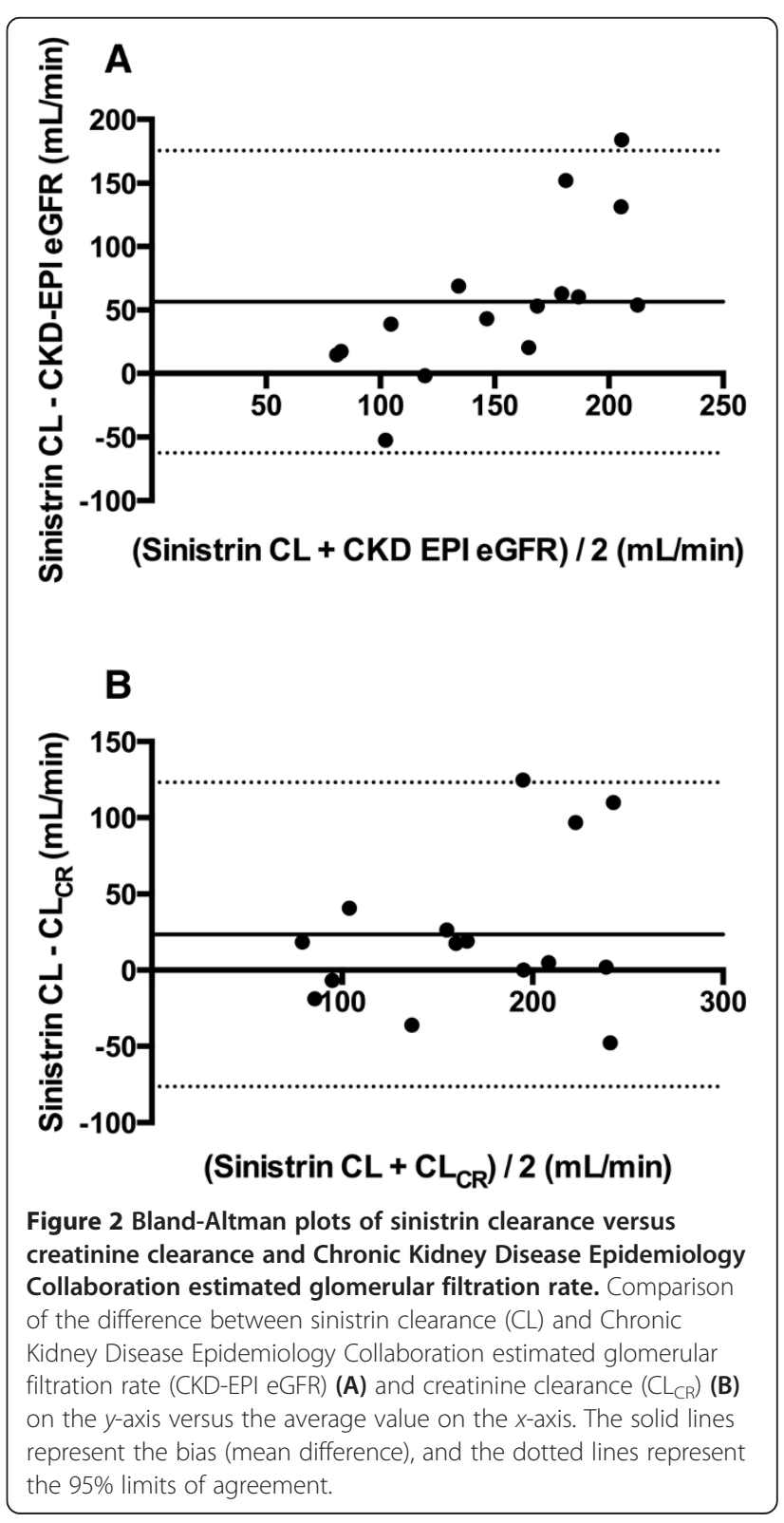


parameters was observed (Table 2). The mean filtration fraction was $34.0 \%$ (25.4\% to $42.7 \%)$. Of note, sinistrin CL was higher than $\mathrm{CL}_{\mathrm{CR}}$, although this was not statistically significant $(P=0.10)$. These measures were highly correlated, however $(r=0.70, P<0.01)$. Bland-Altman plots comparing sinistrin $\mathrm{CL}$ with $\mathrm{CL}_{\mathrm{CR}}$, as well as with CKD-EPI eGFR, are presented in Figure 2. Graphical correlations between sinistin $\mathrm{CL}, \mathrm{CL}_{\mathrm{CR}}, \mathrm{PAH} \mathrm{CL_{ \textrm {R } }}$ and filtration fraction are presented in Figure 3.

rac-Pindolol was administered enterally to 17 patients and fluconazole to 19, without any observed adverse events. Suitable concentration/time profiles could be plotted in 14 cases for $(S)$ - and $(R)$-pindolol and in 18 cases for fluconazole. These are presented in Figures 4 and 5, respectively. Ae, AUC, CL, $C_{R}$ and $C_{\mathrm{NR}}$ values for each marker are presented in Table 2.

\section{Glomerular and tubular functional assessment and combined marker analyses}

GFR, ERPF, net tubular anion secretion, net tubular cation secretion and net tubular reabsorption were calculated as outlined above. These data, in comparison to those previously reported in healthy volunteers, are presented in Table 3.

\section{Discussion}

In comparison with previous data reported in healthy volunteers, by using identical exogenous markers of renal
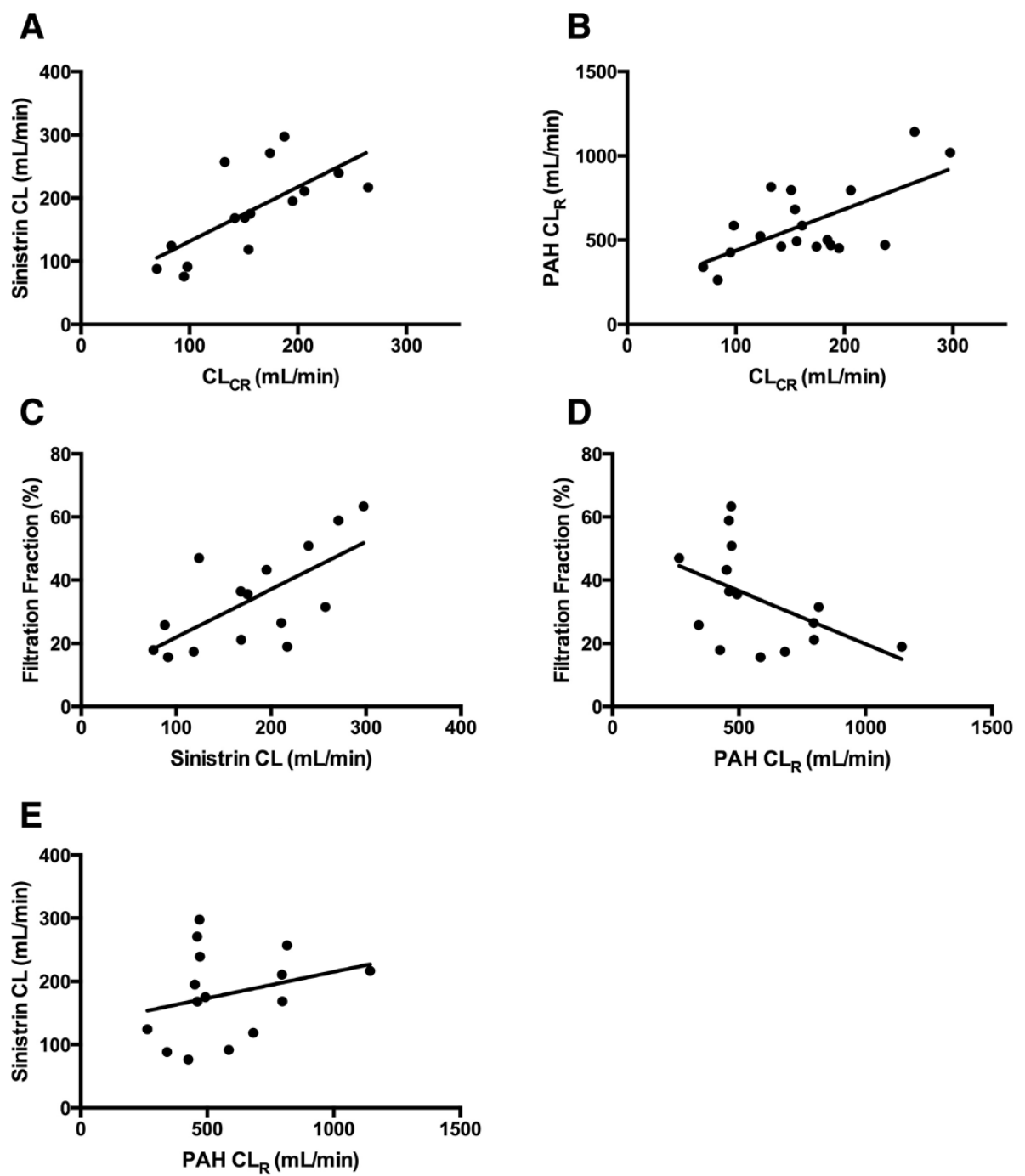

Figure 3 Graphical correlations between sinistrin clearance, creatinine clearance, $p$-aminohippuric acid renal clearance and filtration fraction. (A) Sinistrin clearance $(C L)\left(y\right.$-axis) versus creatinine clearance $\left(C L_{C R}\right)(x$-axis) $(r=0.70, P<0.01)$. (B) p-Aminohippuric acid renal clearance (PAH $\left.C_{R}\right)\left(y\right.$-axis) versus $C_{C R}(x$-axis) $(r=0.65, P<0.01)$. (C) Filtration fraction ( $y$-axis) versus sinistrin $C L(x$-axis) $(r=0.68, P<0.01)$. (D) Filtration fraction ( $y$-axis) versus PAH $C L_{R}$ ( $x$-axis) $(r=-0.49, P=0.06)$. (E) Sinistrin $C L$ ( $y$-axis) versus $P A H C L_{R}(x$-axis) $(r=0.27, P=0.32)$. A linear regression line has been fitted in each case. 


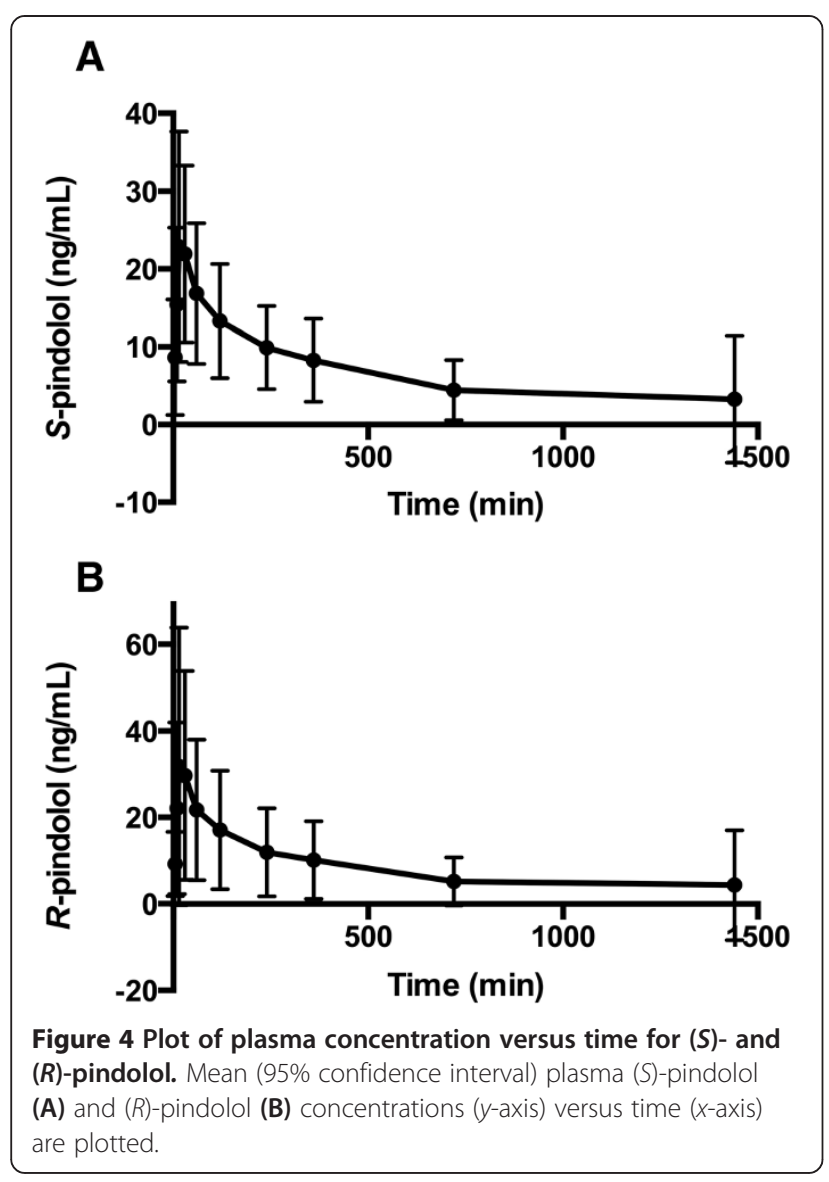

function, we have demonstrated elevated glomerular filtration and renal tubular anion secretion in a selected cohort of critically ill patients at risk of ARC. As these mechanisms are central to $\beta$-lactam renal elimination, the potential for inadequate drug exposure is considerable in this setting [7], an assertion consistent with recent literature $[2-4,15]$.

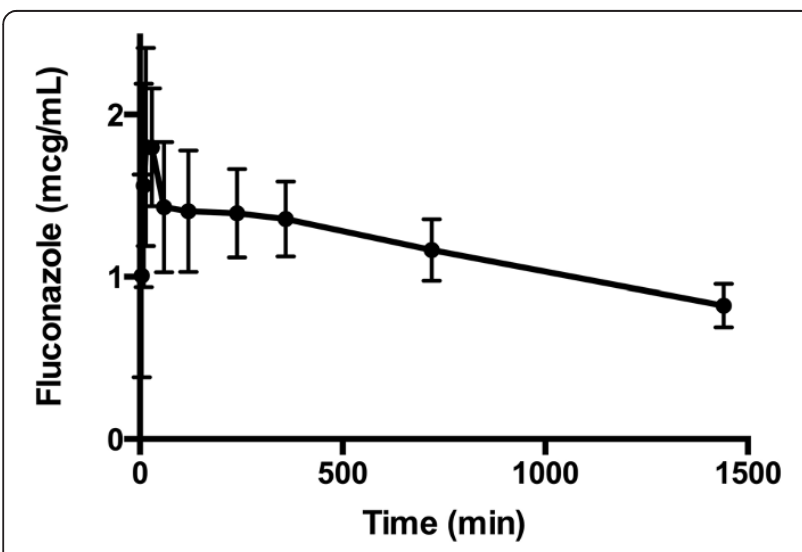

Figure 5 Fluconazole plasma concentration versus time plot. Mean (95\% confidence interval) plasma fluconazole concentration $(y$-axis) versus time $(x$-axis) values are plotted.
Overall, the study protocol was well tolerated by all participants, with no adverse events observed. Furthermore, suitable concentration/time profiles could be generated in most instances, limited primarily by our strict criteria for determining sinistrin $\mathrm{AUC}_{0-\infty}$ [13]. Sinistrin CL in our study was higher (see Table 3) than previously reported in non-critically ill subjects $[9,16,17]$. In keeping with this, $\mathrm{CL}_{\mathrm{CR}}$ measures were also elevated, with good correlation $(r=0.7)$ between these values.

PAH CL was also higher in our cohort, although mechanisms other than renal excretion of unchanged drug accounted for a significant fraction. This process reflects acetylation of PAH [18], which has previously been reported to account for $15 \%$ to $30 \%$ of total drug elimination [18-20]. Fluconazole CL in the critically ill has been reported to be between 0.88 to $2.17 \mathrm{~L} / \mathrm{hr}$ [21]. The findings of the present study are consistent with these previous reports, although fluconazole $\mathrm{CL}_{\mathrm{NR}}$ was significantly elevated in our study. This metabolic pathway involves glucuronide conjugation in the liver, a process that appears to decline in parallel with deteriorating renal function [22]. Of note, total $\mathrm{CL}$ and $\mathrm{CL}_{R}$ of both enantiomers of pindolol were lower than previously reported in healthy volunteers [14].

The reduced $\mathrm{CL}_{\mathrm{R}}$ of rac-pindolol and the suggestion of impaired renal cation secretion were unexpected findings. A likely explanation may involve variation in urinary $\mathrm{pH}$, as previously described by Ujhelyi et al. [23]. In their study, $(S)$ - and $(R)$-pindolol $\mathrm{CL}_{\mathrm{R}}$ was determined in eight healthy male subjects before and after urinary acidification with ammonium chloride. At a mean urinary $\mathrm{pH}$ of 5.0, a twofold increase in $\mathrm{CL}_{R}$ of both isomers was noted [23] and thought to be principally related to an increase in organic transporter activity. In our study, the mean $(95 \% \mathrm{CI})$ urinary $\mathrm{pH}$ was 6.16 (5.75 to 6.57), considerably more alkaline than might have been expected and which may account for the reduced $\mathrm{CL}_{\mathrm{R}}$ observed.

Another potential mechanism impairing rac-pindolol tubular secretion may involve inhibition of the organic cation transport system, as has been demonstrated with co-administration of cimetidine [24]. Of note, this is thought primarily to involve competitive inhibition of the luminal efflux process rather than basolateral uptake [25]. Although none of the study participants were concurrently receiving cimetidine, other medications have been potentially implicated [26], resulting in varying degrees of inhibition. As such, whereas co-administration of the study markers themselves do not generate any interactions $[9,27,28]$, a potential additional drug-drug interaction in our study cohort cannot be excluded.

The observed changes in $\mathrm{CL}_{\mathrm{NR}}$ of both PAH and fluconazole are notable findings. Acetylation of PAH occurs in the liver and kidneys, with the metabolite ( $N$-acetyl-PAH) then excreted in urine [29]. In contrast to previous work [18-20], 
Table 3 Glomerular and tubular functional assessment and combined marker analyses ${ }^{a}$

\begin{tabular}{|c|c|c|c|}
\hline & \multicolumn{2}{|c|}{ Mean $(95 \% \mathrm{Cl})$ (present study) } & \multirow{2}{*}{$\begin{array}{l}\text { Healthy volunteers }{ }^{\mathrm{b}} \text { mean }(\mathrm{SD}) \\
\mathrm{ml} / \mathrm{min}\end{array}$} \\
\hline & $\mathrm{ml} / \mathrm{min} / 1.73 \mathrm{~m}^{2}$ & $\mathrm{ml} / \mathrm{min}$ & \\
\hline Glomerular filtration rate $(n=15)$ & 161 (129 to 193$)$ & 180 (141 to 219$)$ & $143(45)$ \\
\hline Effective renal plasma flow $(n=19)$ & 535 (442 to 628$)$ & 594 (484 to 704$)$ & $467(146)$ \\
\hline \multicolumn{4}{|l|}{ Renal tubular anion secretion $(n=15)$} \\
\hline Net secretion of PAH & 388 (282 to 494$)$ & 428 (306 to 550$)$ & $359(134)$ \\
\hline \multicolumn{4}{|l|}{ Renal tubular cation secretion $(n=10)$} \\
\hline Net tubular secretion of (S)-pindolol & $47(-19$ to 113$)$ & $46(-15$ to 107$)$ & $152(70)$ \\
\hline Net tubular secretion of (R)-pindolol & $25(-16$ to 67$)$ & $24(-17$ to 66$)$ & $132(45)$ \\
\hline \multicolumn{4}{|l|}{ Renal tubular reabsorption $(n=13)$} \\
\hline Net tubular reabsorption of fluconazole & 120 (92 to 148$)$ & 135 (100 to 169$)$ & $93(29)$ \\
\hline
\end{tabular}

${ }^{\mathrm{a}} \mathrm{Cl}$, Confidence interval; PAH, p-Aminohippuric acid; SD, Standard deviation. ${ }^{\mathrm{b}}$ Twelve healthy male subjects (mean age, 24 years; mean weight, $72 \mathrm{~kg} ;$ mean height, $1.78 \mathrm{~m}$ ) with normal laboratory parameters and a Cockcroft-Gault estimated creatinine clearance $>100 \mathrm{ml} / \mathrm{min}$ [9].

plasma PAH CL was significantly elevated in our study, with $\mathrm{CL}_{\mathrm{NR}}$ accounting for, on average, $48 \%$ of total $\mathrm{PAH}$ elimination. Similarly, fluconazole $\mathrm{CL}_{\mathrm{NR}}$ was also elevated, a finding disparate from prior research in the critically ill [30]. This may be a consequence of greater tubular reabsorption of fluconazole, a process driven by increased glomerular filtration. Notwithstanding this, as non-renal elimination of $\mathrm{PAH}$ and fluconazole primarily involve conjugation, these observations remain consistent with increased solute delivery to other drug eliminating organs, such as the liver. Whether augmented hepatic clearance also occurs in this setting remains uncertain, although, given the potentially significant impact of such changes on PK parameters, this represents an essential area for future study.

Elevated $\mathrm{CL}_{\mathrm{CR}}$ has been reported in numerous subgroups, including traumatic brain injury [31], polytrauma [32,33], burns [34], sepsis [35], ventilator-associated pneumonia [36], meningitis [37] and major surgery [38]. Lower illness severity scores [39], younger age [35], male sex [4] and systemic inflammation [40] are common features. Indeed, young male patients admitted post-trauma and without the requirement for vasopressor therapy formed the majority of our study cohort. Activation of renal reserve represents a possible explanation for these findings [41], although data from our study reinforce that changes in GFR in this context are likely more complex. Specifically, for a given ERPF, the filtration fraction varied considerably, accounting for the increased sinistrin CL observed in some patients (Figure 3). These data indicate that changes in intra-glomerular filtration pressure (due to variable afferent and efferent arteriolar tone) are potentially a key mechanism warranting further in-depth study.

CKD-EPI eGFR values were significantly lower than $\mathrm{CL}_{\mathrm{CR}}$ measures, reinforcing the limited utility of these estimates in such patients [42]. $\mathrm{CL}_{\mathrm{CR}}$ measures displayed less bias in comparison to sinistin CL, although precision was poor with either estimate (Figure 2).
Nonetheless, low-normal plasma CR concentrations in young trauma patients without oliguria should alert the clinician to the possibility of ARC, following which a urinary $\mathrm{CL}_{\mathrm{CR}}$ test could be used to reinforce this finding. Of note, the use of $\mathrm{CL}_{\mathrm{CR}}$ as a surrogate outside a population at risk of ARC remains uncertain, particularly given the increasing inaccuracy of this measure with declining renal function [43].

We wish to declare the following limitations. We chose to employ study markers previously validated in healthy volunteers, allowing for direct comparison with a non-critically ill cohort. Our use of enteral pindolol and fluconazole mirror the approach used by Gross et al. [9], although gastrointestinal absorption in the critically ill is often more variable. Importantly, both fluconazole [44] and pindolol [45] have excellent oral bioavailability, and none of the study participants receiving these markers were intolerant of enteral nutrition.

Our sampling interval was also limited to 24 hours, as opposed to longer periods that have been used to characterize fluconazole pharmacokinetics [46]. However, fluconazole $\mathrm{CL}_{\mathrm{R}}$ over this shorter period is comparable with that based on sampling for 120 hours [9], allowing for a shorter study period. Finally, we chose to measure ERPF by using a PAH bolus IV approach rather than constant infusion. Although there has been some criticism of this technique [47], peak concentrations were substantially lower than those known to saturate anion transport in the kidney [19], such that our analyses are likely to provide a reliable measure of PAH CL $\mathrm{R}_{\mathrm{R}}$.

\section{Conclusions}

In this study, we employed multiple exogenous markers to quantify renal elimination pathways in patients at risk of ARC. Increased sinistrin CL (in correlation with a high $\mathrm{CL}_{\mathrm{CR}}$ ) confirms elevated glomerular filtration in these patients. In addition, increases in tubular anion secretion and tubular reabsorption were noted, which may 
also influence renal elimination for drugs subject to these clearance mechanisms. Tubular cation secretion was impaired, although the reason for this observation remains uncertain. Non-renal elimination of PAH and fluconazole were also increased, a finding that warrants further investigation.

\section{Key messages}

- In patients at risk of ARC, sinistrin clearance is elevated, an observation consistent with increased glomerular filtration.

- Sinistrin clearance is moderately correlated with measured creatinine clearance in these patients.

- Increased renal tubular anion secretion and renal tubular reabsorption were also noted in this group.

- Renal tubular cation secretion was impaired, possibly a reflection of changes in urinary $\mathrm{pH}$.

- Non-renal elimination mechanism were also elevated, a finding that warrants further investigation.

\begin{abstract}
Abbreviations
Ae: Amount recovered in urine; APACHE: Acute Physiology and Chronic Health Evaluation; ARC: Augmented renal clearance; $\mathrm{AUC}_{0-\infty}$ : Area under the concentration/time curve extrapolated to infinity; Cl: Confidence interval; CKD: Chronic kidney disease; CKD-EPI: Chronic Kidney Disease Epidemiology Collaboration; $\mathrm{CL}$ : Plasma clearance; $\mathrm{CL}_{\mathrm{CR}}$ : Creatinine clearance; $\mathrm{CL}_{\mathrm{NR}}$ : Non-renal clearance; $\mathrm{CL}_{\mathrm{R}}$ : Renal clearance; $\mathrm{CR}$ : Creatinine; ERPF: Effective renal plasma flow; $f_{\mathrm{u}}$ : Unbound fraction; GFR: Glomerular filtration rate; ICU: Intensive care unit; IDC: Indwelling urinary catheter; IV: Intravenous: PAH: p-Aminohippuric acid; PK: Pharmacokinetic; RIFLE: Risk, injury, failure, loss, end-stage kidney disease criteria; SD: Standard deviation.
\end{abstract}

\section{Competing interests}

$J L$ has acted as a consultant to AstraZeneca and Janssen-Cilag; he has received honoraria from AstraZeneca, Janssen-Cilag and Wyeth Australia; and he was involved with the Bayer European Society of Intensive Care Medicine Advisory Board. JAR has previously consulted for Janssen-Cilag, AstraZeneca, Pfizer and Gilead; he has been involved in advisory boards for Janssen-Cilag and AstraZeneca; and he has received unrestricted grants from Janssen-Cilag, AstraZeneca and Novartis. AAU has received an honorarium and travel assistance from Pfizer. AstraZeneca and Edwards Lifesciences provide an annual unrestricted donation to the Burns, Trauma and Critical Care Research Centre at The University of Queensland. The remaining authors declare that they have no potential conflicts of interest in relation to this article.

\section{Authors' contributions}

AAU and JL conceived of the study. AAU, PJ, JAR, MLS and TS were involved in protocol development, ethical approval and implementation. AAU, PJ, JS, MLS, TS and RD collected the data. SCW completed the laboratory analysis and quality assurance. AAU and JAR provided the statistical and pharmacokinetic analysis. AAU wrote the initial manuscript draft, with all of the remaining authors contributing to subsequent revisions. AAU takes responsibility for archiving the data and guarantees the integrity of the paper from inception to publication. All of the authors read and approved the final manuscript.

\section{Acknowledgements}

AAU was supported in part by a Royal Brisbane and Women's Hospital Foundation Research Grant. JAR is supported in part by the Australian National Health and Medical Research Council (Career Development Fellowship APP1048652). The authors wish to acknowledge the support of colleagues, including medical and nursing staff, in completing the study. The work was performed in the Department of Intensive Care Medicine \& Burns,
Trauma, and Critical Care Research Centre, The University of Queensland, Royal Brisbane and Women's Hospital, Herston, Queensland, Australia.

\section{Author details}

${ }^{1}$ Department of Intensive Care and Hyperbaric Medicine, The Alfred, 55 Commercial Road, Prahran, Melbourne, Victoria 3181, Australia. 'Burns, Trauma, and Critical Care Research Centre, The University of Queensland, Herston, Brisbane, Queensland 4029, Australia. ${ }^{3}$ Department of Intensive Care Medicine, Royal Brisbane and Women's Hospital, Butterfield Street, Herston, Brisbane, Queensland 4029, Australia.

Received: 1 August 2014 Accepted: 11 November 2014

Published online: 29 November 2014

\section{References}

1. Udy AA, Roberts JA, Boots RJ, Paterson DL, Lipman J: Augmented renal clearance: implications for antibacterial dosing in the critically ill. Clin Pharmacokinet 2010, 49:1-16.

2. Conil JM, Georges B, Mimoz O, Dieye E, Ruiz S, Cougot P, Samii K, Houin G, Saivin $S$ : Influence of renal function on trough serum concentrations of piperacillin in intensive care unit patients. Intensive Care Med 2006, 32:2063-2066.

3. Udy AA, Varghese JM, Altukroni M, Briscoe S, McWhinney BC, Ungerer JP, Lipman J, Roberts JA: Subtherapeutic initial $\beta$-lactam concentrations in select critically ill patients: association between augmented renal clearance and low trough drug concentrations. Chest 2012, 142:30-39.

4. Claus BO, Hoste EA, Colpaert K, Robays H, Decruyenaere J, De Waele JJ: Augmented renal clearance is a common finding with worse clinical outcome in critically ill patients receiving antimicrobial therapy. J Crit Care 2013, 28:695-700

5. Baptista JP, Sousa E, Martins PJ, Pimentel JM: Augmented renal clearance in septic patients and implications for vancomycin optimisation. Int $J$ Antimicrob Agents 2012, 39:420-423.

6. Udy A, Roberts JA, Boots RJ, Lipman J: You only find what you look for: the importance of high creatinine clearance in the critically ill. Anaesth Intensive Care 2009, 37:11-13.

7. Lipman J, Udy AA, Roberts JA: Do we understand the impact of altered physiology, consequent interventions and resultant clinical scenarios in the intensive care unit? The antibiotic story. Anaesth Intensive Care 2011, 39:999-1000.

8. Tett SE, Kirkpatrick CM, Gross AS, McLachlan AJ: Principles and clinical application of assessing alterations in renal elimination pathways. Clin Pharmacokinet 2003, 42:1193-1211.

9. Gross AS, McLachlan AJ, Minns I, Beal JB, Tett SE: Simultaneous administration of a cocktail of markers to measure renal drug elimination pathways: absence of a pharmacokinetic interaction between fluconazole and sinistrin, $p$-aminohippuric acid and pindolol. Br J Clin Pharmacol 2001, 51:547-555.

10. Bone RC, Balk RA, Cerra FB, Dellinger RP, Fein AM, Knaus WA, Schein RM, Sibbald WJ: Definitions for sepsis and organ failure and guidelines for the use of innovative therapies in sepsis. The ACCP/SCCM Consensus Conference Committee. American College of Chest Physicians/Society of Critical Care Medicine. Chest 1992, 101:1644-1655.

11. Bellomo R, Ronco C, Kellum JA, Mehta RL, Palevsky P, cute Dialysis Quality Initiative: AAcute renal failure - definition, outcome measures, animal models, fluid therapy and information technology needs: the Second International Consensus Conference of the Acute Dialysis Quality Initiative (ADQI) Group. Crit Care 2004, 8:R204-R212.

12. Johnson DW, Jones GR, Mathew TH, Ludlow MJ, Doogue MP, Jose MD, Langham RG, Lawton PD, McTaggart SJ, Peake MJ, Polkinghorne K, Usherwood T: Chronic kidney disease and automatic reporting of estimated glomerular filtration rate: new developments and revised recommendations. Med J Aust 2012, 197:224-225.

13. Buclin T, Pechère-Bertschi $A$, Séchaud R, Décosterd LA, Munafo A, Burnier M, Biollaz J: Sinistrin clearance for determination of glomerular filtration rate: a reappraisal of various approaches using a new analytical method. J Clin Pharmacol 1997, 37:679-692.

14. Hsyu PH, Giacomini KM: Stereoselective renal clearance of pindolol in humans. J Clin Invest 1985, 76:1720-1726.

15. Carlier M, Carrette S, Roberts JA, Stove V, Verstraete AG, Hoste E, Decruyenaere J, Depuydt P, Lipman J, Wallis SC, De Waele JJ: Meropenem 
and piperacillin/tazobactam prescribing in critically ill patients: Does augmented renal clearance affect pharmacokinetic/pharmacodynamic target attainment when extended infusions are used? Crit Care 2013, 17:R84.

16. Buclin T, Sechaud R, Bertschi AP, Decosterd LA, Belaz N, Appenzeller M, Burnier M, Biollaz J: Estimation of glomerular filtration rate by sinistrin clearance using various approaches. Ren Fail 1998, 20:267-276.

17. Estelberger W, Petek W, Zitta S, Mauric A, Horn S, Holzer H, Pogglitsch H: Determination of the glomerular filtration rate by identification of sinistrin kinetics. Eur J Clin Chem Clin Biochem 1995, 33:201-209.

18. Prescott LF, Freestone S, McAuslane JA: The concentration-dependent disposition of intravenous $\mathrm{p}$-aminohippurate in subjects with normal and impaired renal function. Br J Clin Pharmacol 1993, 35:20-29.

19. Dowling TC, Frye RF, Fraley DS, Matzke GR: Characterization of tubular functional capacity in humans using para-aminohippurate and famotidine. Kidney Int 2001, 59:295-303

20. Cole BR, Giangiacomo J, Ingelfinger JR, Robson AM: Measurement of renal function without urine collection-a critical evaluation of the constantinfusion technic for determination of inulin and para-aminohippurate. N Engl J Med 1972, 287:1109-1114.

21. Sinnollareddy M, Peake SL, Roberts MS, Playford EG, Lipman J, Roberts JA: Pharmacokinetic evaluation of fluconazole in critically ill patients. Expert Opin Drug Metab Toxicol 2011, 7:1431-1440.

22. Toon S, Ross CE, Gokal R, Rowland M: An assessment of the effects of impaired renal function and haemodialysis on the pharmacokinetics of fluconazole. Br J Clin Pharmacol 1990, 29:221-226.

23. Ujhelyi MR, Bottorff MB, Schur M, Roll K, Zhang $H$, Stewart J, Markel ML: Urine acidification affects the activity of the organic base transporter in a nonstereoselective manner. J Pharmacol Exp Ther 1996, 276:683-689.

24. Somogyi AA, Bochner F, Sallustio BC: Stereoselective inhibition of pindolol renal clearance by cimetidine in humans. Clin Pharmacol Ther 1992, 51:379-387.

25. Ito S, Kusuhara H, Yokochi M, Toyoshima J, Inoue K, Yuasa H, Sugiyama Y: Competitive inhibition of the luminal efflux by multidrug and toxin extrusions, but not basolateral uptake by organic cation transporter 2, is the likely mechanism underlying the pharmacokinetic drug-drug interactions caused by cimetidine in the kidney. J Pharmacol Exp Ther 2012, 340:393-403

26. Wittwer MB, Zur AA, Khuri N, Kido Y, Kosaka A, Zhang X, Morrissey KM, Sali A, Huang $Y$, Giacomini KM: Discovery of potent, selective multidrug and toxin extrusion transporter 1 (MATE1, SLC47A1) inhibitors through prescription drug profiling and computational modeling. J Med Chem 2013, 56:781-795.

27. McLachlan AJ, Gross AS, Beal JL, Minns I, Tett SE: Analytical validation for a series of marker compounds used to assess renal drug elimination processes. Ther Drug Monit 2001, 23:39-46.

28. Wainer $E$, Boner $G$, Rosenfeld JB: Effects of pindolol on renal function. Clin Pharmacol Ther 1980, 28:575-580.

29. Lee $L$, Smith DE: Renal excretion and metabolism of $p$-aminohippurate in the isolated perfused rat kidney. Pharm Res 1988, 5:745-747.

30. Buijk SL, Gyssens IC, Mouton JW, Verbrugh HA, Touw DJ, Bruining HA: Pharmacokinetics of sequential intravenous and enteral fluconazole in critically ill surgical patients with invasive mycoses and compromised gastro-intestinal function. Intensive Care Med 2001, 27:115-121.

31. Udy A, Boots R, Senthuran S, Stuart J, Deans R, Lassig-Smith M, Lipman J: Augmented creatinine clearance in traumatic brain injury. Anesth Analg 2010, 111:1505-1510.

32. Udy AA, Baptista JP, Lim NL, Joynt GM, Jarrett P, Wockner L, Boots RJ, Lipman J: Augmented renal clearance in the ICU: results of a multicenter observational study of renal function in critically III patients with normal plasma creatinine concentrations. Crit Care Med 2014, 42:520-527.

33. Minville V, Asehnoune K, Ruiz S, Breden A, Georges B, Seguin T, Tack I, Jaafar A, Saivin S, Fourcade O, Samii K, Conil JM: Increased creatinine clearance in polytrauma patients with normal serum creatinine: a retrospective observational study. Crit Care 2011, 15:R49.

34. Conil JM, Georges B, Fourcade O, Seguin T, Lavit M, Samii K, Houin G, Tack I, Saivin S: Assessment of renal function in clinical practice at the bedside of burn patients. Br J Clin Pharmacol 2007, 63:583-594.
35. Udy AA, Roberts JA, Shorr AF, Boots RJ, Lipman J: Augmented renal clearance in septic and traumatized patients with normal plasma creatinine concentrations: identifying at-risk patients. Crit Care 2013, 17:R35.

36. Ambrose PG, Bhavnani SM, Ellis-Grosse EJ, Drusano GL: Pharmacokineticpharmacodynamic considerations in the design of hospital-acquired or ventilator-associated bacterial pneumonia studies: Look before you leap! Clin Infect Dis 2010, 51:S103-S110.

37. Lautrette A, Phan TN, Ouchchane L, Aithssain A, Tixier V, Heng AE, Souweine B: High creatinine clearance in critically ill patients with community-acquired acute infectious meningitis. BMC Nephrol 2012, 13:124.

38. Brown R, Babcock R, Talbert J, Gruenberg J, Czurak C, Campbell M: Renal function in critically ill postoperative patients: sequential assessment of creatinine osmolar and free water clearance. Crit Care Med 1980, 8:68-72

39. Fuster-Lluch O, Gerónimo-Pardo M, Peyró-García R, Lizán-García M: Glomerular hyperfiltration and albuminuria in critically ill patients. Anaesth Intensive Care 2008, 36:674-680.

40. Shimamoto Y, Fukuda T, Tanaka K, Komori K, Sadamitsu D: Systemic inflammatory response syndrome criteria and vancomycin dose requirement in patients with sepsis. Intensive Care Med 2013, 39:1247-1252.

41. Thomas DM, Coles GA, Williams JD: What does the renal reserve mean? Kidney Int 1994, 45:411-416.

42. Udy AA, Morton FJ, Nguyen-Pham S, Jarrett P, Lassig-Smith M, Stuart J, Dunlop R, Starr T, Boots RJ, Lipman J: A comparison of CKD-EPI estimated glomerular filtration rate and measured creatinine clearance in recently admitted critically ill patients with normal plasma creatinine concentrations. BMC Nephrol 2013, 14:250.

43. Bragadottir G, Redfors B, Ricksten SE: Assessing glomerular filtration rate (GFR) in critically ill patients with acute kidney injury - true GFR versus urinary creatinine clearance and estimating equations. Crit Care 2013, 17:R108.

44. Nicolau DP, Crowe H, Nightingale CH, Quintiliani R: Bioavailability of fluconazole administered via a feeding tube in intensive care unit patients. J Antimicrob Chemother 1995, 36:395-401.

45. Meier J, Nuesch E: Pindolol, a $\beta$-adrenoceptor blocking agent with a negligible first-pass effect. Br J Clin Pharmacol 1977, 4:371-372.

46. Debruyne D: Clinical pharmacokinetics of fluconazole in superficial and systemic mycoses. Clin Pharmacokinet 1997, 33:52-77.

47. Hirata-Dulas CA, Awni WM, Matzke GR, Halstenson CE, Guay DR: Evaluation of two intravenous single-bolus methods for measuring effective renal plasma flow. Am J Kidney Dis 1994, 23:374-381.

doi:10.1186/s13054-014-0657-z

Cite this article as: Udy et al:: Determining the mechanisms underlying augmented renal drug clearance in the critically ill: use of exogenous marker compounds. Critical Care 2014 18:657.

\section{Submit your next manuscript to BioMed Central and take full advantage of:}

- Convenient online submission

- Thorough peer review

- No space constraints or color figure charges

- Immediate publication on acceptance

- Inclusion in PubMed, CAS, Scopus and Google Scholar

- Research which is freely available for redistribution 